\title{
Improving the success rate of business process re-engineering projects: A business process re-engineering framework
}

\begin{tabular}{|c|c|}
\hline \multicolumn{2}{|c|}{$\begin{array}{l}\text { Authors: } \\
\text { Aphelele Nkomo }{ }^{1} \\
\text { Carl Marnewick }^{1}\end{array}$} \\
\hline \multicolumn{2}{|c|}{$\begin{array}{l}\text { Affiliations: } \\
\text { 'Department of Applied } \\
\text { Information Systems, College } \\
\text { of Business and Economics, } \\
\text { University of Johannesburg, } \\
\text { Johannesburg, South Africa }\end{array}$} \\
\hline \multicolumn{2}{|c|}{$\begin{array}{l}\text { Corresponding author: } \\
\text { Carl Marnewick, } \\
\text { cmarnewick@uj.ac.za }\end{array}$} \\
\hline \multicolumn{2}{|c|}{$\begin{array}{l}\text { Dates: } \\
\text { Received: } 26 \text { May } 2020 \\
\text { Accepted: } 20 \text { Jan. } 2021 \\
\text { Published: } 01 \text { Mar. } 2021\end{array}$} \\
\hline \multicolumn{2}{|c|}{$\begin{array}{l}\text { How to cite this article: } \\
\text { Nkomo, A. \& Marnewick, C., } \\
\text { 2021, 'Improving the success } \\
\text { rate of business process } \\
\text { re-engineering projects: } \\
\text { A business process } \\
\text { re-engineering framework', } \\
\text { South African Journal of } \\
\text { Information Management } \\
\text { 23(1), a1259. https://doi. } \\
\text { org/10.4102/sajim.v23i1.1259 }\end{array}$} \\
\hline \multicolumn{2}{|c|}{$\begin{array}{l}\text { Copyright: } \\
\text { (c) 2021. The Authors } \\
\text { Licensee: AOSIS. This } \\
\text { is licensed under the } \\
\text { Creative Commons } \\
\text { Attribution License. }\end{array}$} \\
\hline \multicolumn{2}{|l|}{ Read online: } \\
\hline 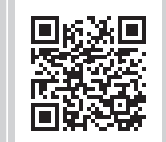 & $\begin{array}{l}\text { Scan this QR } \\
\text { code with your } \\
\text { smart phone or } \\
\text { mobile device } \\
\text { to read online. }\end{array}$ \\
\hline
\end{tabular}

Background: Financial institutions in South Africa are implementing business process re-engineering (BPR) on a regular basis because of the fast-changing industry. However, the success of these projects is low because of the lack of clearly defined roles, an unclear definition of what BPR is, the inability to link BPR projects to organisation strategies and the lack of documentation to guide BPR activities. Accordingly, there is a need to define a framework to guide the implementation of BPR projects.

Objectives: The researchers embarked on this study in order to define a framework to ensure improvement of BPR in financial institutions. The framework should assist in providing guidelines when conducting BPR activities and will enable plans for BPR projects in terms of knowing which skills and roles to source for these projects.

Method: A conceptual BPR framework was developed and BPR experts from financial institutions were then engaged to determine whether the framework would work. The engagements included understanding the challenges faced and how they could be combated, understanding the roles involved and determining if organisations had BPR frameworks in place. This subsequently led to a final framework being consolidated.

Results: This study presents the recommended BPR framework that can be used by financial institutions to achieve success in their projects. The framework incorporates project management and change management processes and ensures alignment of BPR activities with the project phases. It also ensures that the activities are clearly stipulated and the roles performing the activities are clearly defined. It considers time management, planning aspects and effective communication within BPR projects.

Conclusion: The proposed framework can be used by financial institutions to manage their re-engineering projects. This framework overcomes most of the known challenges and combines two disciplines, that is, project management and business process re-engineering.

Keywords: business process re-engineering (BPR); challenges; roles; success factors; BRP framework; qualitative study; interviews.

\section{Introduction}

Hammer and Champy (1993:53) defined business process re-engineering (BPR) as a 'fundamental rethinking and radical redesign of business processes to achieve dramatic improvements in critical measures of performance, such as cost, quality, service and speed'. BPR initiatives are conducted by organisations in order to understand their current business processes and to define how those processes can be optimised. This is necessary as new processes, organisational structures or systems arise (Evans, Mason-Jones \& Towill 1999).

Organisations therefore undertake BPR projects to optimise the performance of current or new processes with the ultimate goal of improving productivity and performance of the organisation.

BPR initiatives fail because organisations lack standard approaches to guide people when performing BPR initiatives (Darmani \& Hanafizadeh 2013; For Choi \& Chan 1997). The lack of standardisation makes it difficult for BPR experts to document and analyse business processes (Indulska et al. 2009). Lack of standards leads to difficulties in understanding the information and sharing it, amongst other things, within the organisation (Kostoff 1999). 
Vakola and Rezgui (2000) emphasised that the success of BPR depends on the approaches that are applied. The approaches selected are critical as they are used to provide control and to guide and manage the changes being implemented (Markus \& Jacobson 2010). Furthermore, approaches are used to ensure that there is a certain way of conducting BPR projects throughout organisations (Kettinger, James \& Guha 1997). The desired approach is where BPR expectations are clearly stated, the role of each team member is clearly articulated and the communication structures are addressed and agreed upon (Santana et al. 2011).

Financial institutions are not excluded from these challenges and also need to focus on appropriate approaches.

The reason for this is that financial institutions are in a continuous process flux as they upgrade or implement new systems. However, financial institutions experience a gap when it comes to defining appropriate methodologies for BPR initiatives (Bucher \& Winter 2009). Therefore, there is a need to define clear methods and governance mechanisms that will assist in ensuring that process modelling becomes a less complex task for financial institutions and that the BPR project success rate is improved (Chakraborty \& Leyer 2013).

Currently, there are no BPR methodologies or governance documents to which financial institutions can refer when conducting BPR initiatives. As a result, the success of BPR initiatives is compromised (Chakraborty \& Leyer 2013). The failure rate of BPR projects conducted in financial institutions indicates that the concept of BPR is not yet clear to employees. Therefore, there is a need for clearly defined methods and structures to ensure the success of BPR initiatives (Kader \& Dwolatzky 2016). This is also applicable to financial institutions.

Given this introduction, the following questions were posed:

- What are the roles and responsibilities associated with BPR initiatives?

- What are the constraints or challenges faced when conducting BPR initiatives?

- What enables success in BPR initiatives?

- What are the components that should be included in a BPR framework to ensure success?

This article consists of six sections. Section 'Introduction' presents the background. Section 'Literature review' covers the literature review, which depicts what BPR is, as well as challenges currently experienced. It also depicts the framework that is defined from the literature review. Section 'Research methodology' deals with the research methodology, research design, tools used to collect the data and analysis method. Section 'Results and analysis' presents findings and section 'Discussions' links the results from the research to the literature review. Lastly, Section 'Conclusion' presents conclusions drawn from the study.
The next section focuses on the literature reviewed for the purpose of this study.

\section{Literature review}

BPR is an approach that is used to evaluate organisational core processes (Luca 2014). The BPR approach includes the introduction of new business processes and assists organisations in determining the types of skills and people required to create multidimensional jobs (Luca 2014; Mendling, Reijers \& Cardoso 2007). BPR ensures that organisations remain effective and competitive even when economic changes are being introduced into the market (Seethamraju \& Marjanovic 2009). It enables organisations to shift from focusing on a silo approach to introducing new processes, to an integrated approach that considers how the new processes are going to affect other departments (Climent, Mula \& Hernández Jorge 2009). This enables organisations to reduce costs and time taken to perform activities, and it ensures that time is diverted to satisfying customers (Vikas \& Bharti 2018).

The implementation of BPR depends highly on the human element (Luca 2014; Vakola \& Rezgui 2000).

However, there are challenges related to employees and managers resisting BPR initiatives because of a fear of losing their jobs and not understanding the BPR concept (Madushela \& Pretorius 2017). Therefore, BPR implementers need to ensure that employees understand why the changes are being made in order for them to not resist BPR initiatives (Vakola \& Rezgui 2000). Financial institutions therefore ought to clearly define BPR strategies to ensure that there are no challenges related to employees resisting change that is brought about through BPR initiatives (Vakola \& Rezgui 2000). The strategies could potentially assist with providing clear definitions of what BPR is all about and clear steps of how it should be conducted.

The term 'business process' refers to the activities that are performed in an organisation to serve customers. Lindsay, Downs and Lunn (2003) describe a business process as a step-by-step grouping of activities, which follow a certain sequence in order to produce a certain product or service. According to Lindsay et al. (2003), business processes need to be improved regularly for them to be effective. This enables organisations to find better ways of improving their operations in order to become more efficient when delivering goods and services to customers.

The documentation of business processes enables an organisation to have a clear view of its processes and bottlenecks in order to introduce improvements such as the automation or elimination of unnecessary activities. This in turn leads to the improvement of its operations and differentiates the organisation from other organisations.

Clear business processes within an organisation assist in reducing costs, time and effort when performing 
organisational activities. Small improvements to one activity can lead to an overall improvement of the entire process and, in turn, can make the organisation much more efficient and better than its competitors.

Hammer and Champy (1993:53) defined BPR as a 'fundamental rethinking and radical redesign of business processes to achieve dramatic improvements in critical measures of performance, such as cost, quality, service and speed'. It is about identifying opportunities for redesigning processes whilst considering the impact that the redesign may have on the costs, quality and flexibility of a business process.

The anticipated measurable outcomes of BPR initiatives include reduced cost, improved quality and increased production (Swartz 2018). BPR is conducted at a strategic level of an organisation and focuses on eliminating processes that do not add value (Swartz 2018). It is conducted by applying certain methodologies, tools and techniques to recommend solutions to problems. The assessment of the mission of an organisation and the organisation's planned goals are considered whilst taking into account customer needs. This includes consideration of the current and future state of the organisation (Novikov et al. 2016).

BPR can only be conducted once an organisation has established its core competencies and the types of people needed to fulfil the organisation's mandate (Swartz 2018). Organisations need to understand their current business processes and how those processes can be improved. The improvements are carried out by introducing new processes, organisational structures or systems.

Methodologies in BPR are critical as they are used to provide control, guidance and management (Markus \& Jacobson 2010). Furthermore, they are used to ensure that there is a certain way of conducting BPR projects throughout organisations (Kettinger et al. 1997). This is where BPR expectations are clearly stated, the role of each team member is clearly articulated and the communication structures are addressed and agreed upon (Santana et al. 2011).

There are multiple methodologies in BPR (Attaran 2004). The most used approaches include the Davenport methodology and the Hammer and Champy methodology (Madushela \& Pretorius 2017). To select the best-suited BPR approach, organisations must consider their objectives, their abilities and their competition.

Ringim, Razalli and Hasnan (2011) stated that the success of BPR in financial institutions is something that has not been investigated thoroughly. Madushela and Pretorius (2017) indicated that the success rate of BPR initiatives is estimated to be at $30 \%$. They further state that the $70 \%$ failure rate is linked to the human element that is sometimes neglected when conducting BPR initiatives (Madushela \& Pretorius 2017).
According to Kader and Dwolatzky (2016), South African financial institutions have not been succeeding with BPR initiatives because of the methodologies they have adopted. Hammer and Champy (quoted by Swartz [2018:39]) stated that 'an estimated 50 to $70 \%$ of BPR projects fail to achieve dramatic results'. This includes projects in financial institutions. The failure is caused by organisations resisting change (Swartz 2018).

Kader and Dwolatzky (2016) postulated that the four major banks in South Africa use Lean and Six Sigma approaches to conduct process re-engineering. The Six Sigma approach focuses on ensuring that a strategic process reaches a particular performance level. Lean is derived from Six Sigma. It is used to address process incompetence and usability whilst focusing on eliminating wasteful activities in a process. Lean and Six Sigma approaches can be used together in one intersecting approach called Lean Six Sigma.

In order to implement Six Sigma, every employee needs to be certified in either green or black belt (Antony 2004). This is, however, a problem because there is no standardisation of how the certifications are weighed by examination bodies; therefore, obtaining these belts does not mean that employees are equally knowledgeable and skilled (Antony 2004). Six Sigma is biased as it assumes that BPR takes place because of defects in a process, whereas re-engineering initiatives can take place in an attempt to reduce risks, costs and time taken to perform a process. Therefore, the conclusion is that the methodologies that financial institutions have used have not yielded successful BPR projects. This then means that the topic could be explored to seek a methodology that would be suitable for financial institutions.

The BPR experts include the roles depicted in Table 1 (Long 2012).

The skills required for BPR include process modelling, facilitation skills, systems thinking, process analysis and design, change management, project management and performance management. These skills are required in BPR initiatives to ensure their success. In other words, when financial institutions hire BPR resources, they have to look for people with these skills.

Half of the BPR projects implemented in the early stages fail or do not achieve the intended goals (Kumar \& Bhatia 2012; Madushela \& Pretorius 2017). Some of the reasons why BPR projects fail are as follows:

- Definitions: Even though most organisations have started embarking on the BPR journey, there are no clear definitions of BPR or the concept of BPR. The concept is interpreted differently by BPR workers and key stakeholders (Vom Brocke et al. 2014). Specialists do not know what BPR should be used for because some are of the view that it should be used for radical changes and some are of the view that it can also be used for incremental changes (Van der Aalst, La Rosa \& Santoro 2016). These uncertainties regarding the BPR definition make it 
TABLE 1: Business process re-engineering experts' roles and responsibilities.

\begin{tabular}{|c|c|}
\hline Role & Responsibility \\
\hline Process champion & $\begin{array}{l}\text { Process champions are senior managers who initiate and support a project within their areas of responsibility. They drive the BPR } \\
\text { initiative, ensure its success and manage the tasks within the process. This role consists of these tasks: } \\
\text { - leading the development of business processes } \\
\text { - coordinating with process owners to provide smooth hand-offs } \\
\text { - gcting as a subject matter expert and providing information advice on process content } \\
\text { - mang and facilitating the development of the process to ensure its success } \\
\text { manflicts relating to the processes }\end{array}$ \\
\hline Process owner & $\begin{array}{l}\text { Process owners are regarded as the business experts of the process. They take ownership of the process to establish accountability. Their } \\
\text { role includes: } \\
\text { - defining the business case for the process } \\
\text { - integrating the process into the line organisation } \\
\text { - ensuring that proper key performance indicators are set } \\
\text { - monitoring and supporting process development }\end{array}$ \\
\hline Process manager & $\begin{array}{l}\text { Process Managers evaluate and improve current business processes. They ensure the efficiency of operational business operations, and } \\
\text { initiate and implement changes or improvements to business processes as required. Their role includes: } \\
\text { - organising tools and techniques to be used for BPR } \\
\text { - assisting in providing training throughout the organisation }\end{array}$ \\
\hline $\begin{array}{l}\text { Business process management office } \\
\text { (BPMO) }\end{array}$ & $\begin{array}{l}\text { The BPMO is the centre of excellence with regard to process design, development and integration. Its role includes: } \\
\text { - developing, owning and maintaining the modelling standards and methodology } \\
\text { - facilitating the integration between business units } \\
\text { - ensuring change control on processes } \\
\text { - ensuring that the business implements these changes consistently } \\
\text { - programme management within the BPR and system implementation project } \\
\text { - creating reach for best practice }\end{array}$ \\
\hline
\end{tabular}

Source: Long, K.A., 2012, 'Process roles - Who are the process owners?', Business Rules Journal 13(9), viewed 13 May 2020, from http://www.brcommunity.com/a2012/b668.html.

$B P R$, business process re-engineering.

difficult for organisations to measure the success of their BPR initiatives (Mmereki \& Moruisi 2013).

- Lack of monitoring: Projects fail when the timelines and progress are not closely monitored (Mmereki \& Moruisi 2013). BPR requires that re-engineered processes and systems be monitored continuously and improved after implementation, otherwise their value deteriorates.

- Resistance to change: According to Mmereki and Moruisi (2013), the success of BPR initiatives is driven by top managers. Some challenges are, therefore, experienced when the managers who are supposed to encourage BPR initiatives resist and refuse to conduct BPR activities (Mmereki \& Moruisi 2013). It also becomes a problem when BPR workers resist new methods of conducting $\mathrm{BPR}$ and they end up being unproductive at work. The resistance is caused by workers who are afraid that reengineering will make them redundant in the company (Madushela \& Pretorius 2017). Employees also feel that assisting in rolling out BPR activities creates more work for them as they must still do their daily job (Darmani \& Hanafizadeh 2013; Mmereki \& Moruisi 2013).

- Methodology: Organisations sometimes embark on the journey of BPR without a clear understanding of what needs to be changed. Therefore, the initiatives are performed on a trial-and-error basis and result in failure. Organisations are struggling with finding methodologies that they can use.

- Lack of planning and communication: BPR projects fail because of a lack of proper planning and communication of key project steps. Project managers do not communicate the BPR implementation plan to the re-engineering team, who needs to be involved in the implementation. Consequently, the re-engineering team implements tasks that are not part of the scope (Mmereki \& Moruisi 2013).

- Selection of inadequate tools: Modelling tools have a direct impact on the failure or success of a project as they enable standardisation across organisations. Some organisations face difficulties with regard to the selection of the right tools when conducting BPR activities and this can result in project failure (Aguilar-Savén 2004). The selection of inadequate tools compromises the quality of projects as the organisations then do not achieve the set objectives.

- Lack of experience: The lack of experience of those who are supposed to conduct BPR, such as process analysts and process champions, can lead to their delivering work that is not up to standard and, in turn, failure may be experienced (Seethamraju \& Marjanovic 2009).

- Slow review/approval process: The review and approval process that the management team must undertake in each stage of BPR can affect the BPR project if not done correctly and on time (Darmani \& Hanafizadeh 2013). Therefore, management commitment is vital for a BPR project to succeed. The process workers also have to ensure that leaders are involved earlier in the project in order to get buy-in from those who are supposed to approve certain milestones (Seethamraju \& Marjanovic 2009).

- Change management focus: BPR projects fail because of lack of proper change management focusing on people and cultural issues. In addition, the change management team does not properly manage the fears of the staff to avoid resistance to change in order for the staff to embrace the BPR efforts. One of the major tools used for change management is constant communication to empower staff, keep them informed and create a sense of ownership in them (Swartz 2018).

Several factors that can be used to counter the challenges that are experienced in BPR initiatives are as follows:

- Defining project expectations: To reduce failure of BPR projects, the aims and objectives expected to be produced by the BPR projects should be stated clearly and reviewed and amended constantly as and when required (Santana et al. 2011). These expectations from the BPR initiative must also be communicated to each team member at the 
start of the project to eliminate misunderstandings in the middle of a BPR project (Amoroso 1998).

- Proper gap analysis: Gap analysis and benchmark studies need to be conducted thoroughly in order to clearly state what the organisation is lacking and then compare it with what is available in order to recommend areas of improvement in current processes.

- Change management: Organisations should define change management strategies. Their leaders should be responsible for ensuring that the employees are updated on the changes that will be introduced; this should be done early in the project (Van der Aalst et al. 2016). According to Madushela and Pretorius (2017), BPR initiatives would be successful if change strategies were introduced by organisations, as the stakeholders would be open to change and not resist it.

- Good communication: A communication plan needs to be introduced at the beginning of the project in order to keep those involved in the BPR project updated. This plan is also implemented in order to constantly review the people's opinion regarding the change that will be introduced (Darmani \& Hanafizadeh 2013).

- Clear documentation: Documentation should be implicit and interpreted in the same manner by everyone (Van der Aalst et al. 2016). This can be done by adopting suitable tools that are easy to use and easily understood.

- Thorough training: Conversely, all the key users should be thoroughly trained to ensure effective use of these tools and obtain maximum benefits from them (Foerster, Engels \& Schattkowsky 2005).

- Leadership commitment: The commitment from top leaders of organisations must be obtained for them to provide support to the team and to ensure that governance is followed, and approvals are not delayed (Amoroso 1998).

\section{Research methodology}

Research is a process of attempting to obtain a better understanding of what causes a specific problem or to determine why things are happening the way they are. Qualitative research is a popular research method used when the researcher requires data from a natural setting (Yin 2014). It is about understanding a social phenomenon and looking at relations within a system. Qualitative research concentrates on three main extents, which are individuals, societies and cultures. A qualitative approach was followed to validate the conceptual BPR framework and to understand how BPR activities are currently conducted. The reason for the qualitative approach was that the researcher's primary objective was to understand perceptions, frustrations and successes experienced regarding BPR.

The literature review was used to develop a BPR framework. The framework was validated and scrutinised through the empirical component, which consisted of conducting face-toface interviews with BPR experts. These experts indicated whether the conceptual framework was suitable for their day-to-day BPR needs, based on real experiences. The BPR experts from financial institutions were identified as people who were able to provide valuable input to the process of defining a BPR framework as they were able to share their current experiences and what worked or what did not.

Semi-structured interviews were identified as the appropriate data tool to be used. Questions were prepared to assist the researcher during the interviews with specific objectives in mind. A framework as seen in Figure 1 was adopted for this research (ed. Flick 2013).

The framework assisted in identifying similar responses and variances from the interviews conducted. It also assisted in drawing a conclusion on a BPR framework suitable for financial institutions (Flick 2013).

\section{Ethical consideration}

Ethical approval to conduct the study was obtained from the University of Johannesburg, College of Business and Economics (reference no. 2019SCiiS06). Participation in this study was voluntary and confidential, and participants were allowed to withdraw from the interview at any stage without any consequences. The questionnaire did not request any personal information from the respondents and no information was reported on an individual basis.

\section{Results and analysis}

This section presents the findings and key outcomes obtained from the interviews with regard to building a BPR framework for financial institutions to determine whether it can be used by BPR experts as a guide when undertaking BPR initiatives.

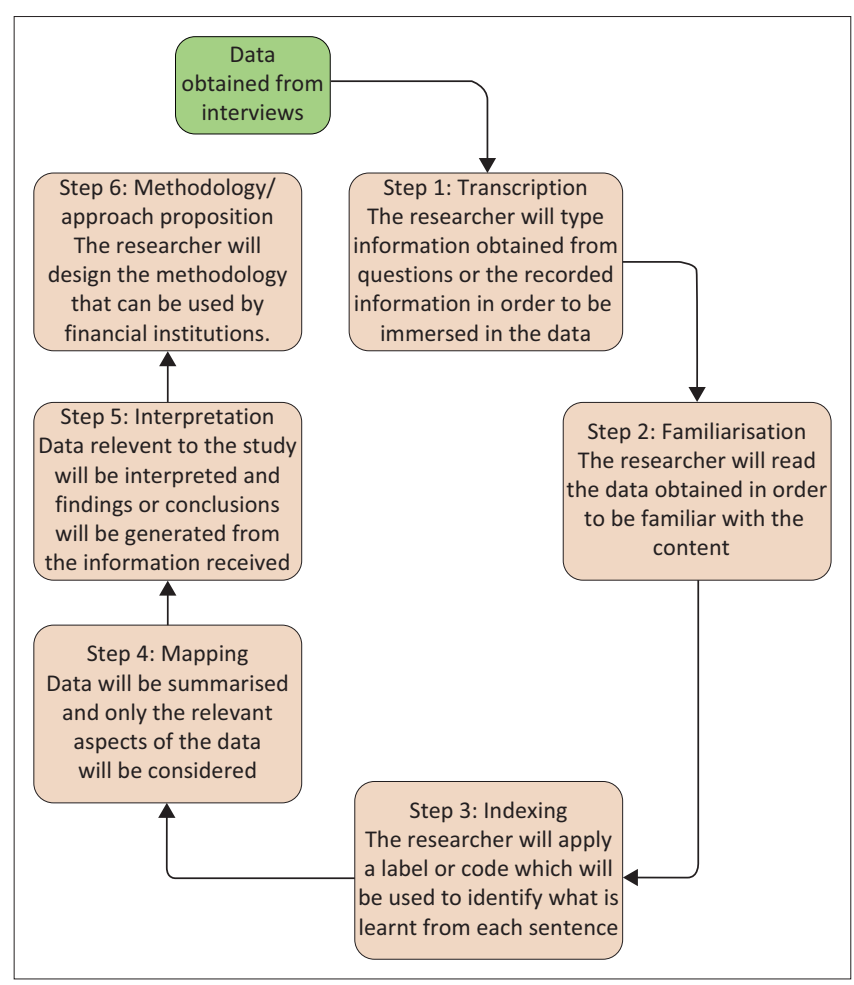

Source: Adapted from Flick, U. (ed.), 2013, The SAGE handbook of qualitative data analysis, SAGE, London.

FIGURE 1: Qualitative data analysis process. 
TABLE 2: Interviewee details.

\begin{tabular}{llcc}
\hline Name & Role & $\begin{array}{c}\text { Interviewee } \\
\text { identifier }\end{array}$ & $\begin{array}{c}\text { Duration } \\
\text { (minutes) }\end{array}$ \\
\hline Interviewee 1 & Business Process Re-engineer & Int_1 & 16 \\
Interviewee 2 & Functional Consultant & Int_2 & 20 \\
\hline Interviewee 3 & IT Applications Portfolio Manager & Int_3 & 14.44 \\
Interviewee 4 & Business Process Re-engineer & Int_4 & 12.51 \\
Interviewee 5 & Business Process Specialist & Int_5 & 12.21 \\
Interviewee 6 & Business Process Specialist & Int_6 & 18.33 \\
Interviewee 7 & Business Process Specialist & Int_7 & 10 \\
Interviewee 8 & Business Process Specialist & Int_8 & 16 \\
Interviewee 9 & Business Analyst & Int_9 & 20 \\
Interviewee 10 & Enterprise Architect & Int_10 & 45 \\
Interviewee 11 & Transformation Support Analyst & Int_11 & 26 \\
\hline Total & - & - & $\mathbf{2 1 0 . 4 9}$ \\
\hline
\end{tabular}

The changes to the conceptual framework as suggested by the interviewees are highlighted. Lastly, the recommended framework, which considers the changes recommended by the interviewees is presented.

The breakdown of the interviewees, the code to identify each interviewee and the time it took to converse with each interviewee are given in Table 2.

\section{Roles and responsibilities}

The first section of the interview dealt with the roles that the interviewees held in the respective financial institutions. This section is linked with the first research question. The results show that four interviewees occupied the role of business process specialist, two occupied the role of business process engineer and the other five occupied the roles of business analyst, transformation support analyst, functional consultant, IT applications portfolio manager and enterprise architect, respectively. This implies that the roles of people can differ from the duties they perform. It therefore indicates the importance of understanding what each role entails.

The key responsibilities in the roles performed by interviewees were identified to determine whether interviewees performed work related to BPR. Process analysis and process optimisation emerged as the main aspects that interviewees performed in their respective roles. Process optimisation is closely associated with process analysis, as it seems to be performed to improve a particular process that is not performing as required, and this is done after process analysis:

'It involves analysing company's workflows, identifying processes that are inefficient and finding ways to improve them with the goal of improving quality, reducing costs and improving productivity'. (Int_1, Gender undisclosed, BPR)

'I am focusing more on optimising business processes by analysing the current processes recommended by the departments that we have and basically recommending better ways of changing those processes to make them more efficient and effective through process optimisation'. (Int_4, Gender undisclosed, BPR)

When comparing the roles that the interviewees were given in the organisations and the duties they performed, it can be concluded that title alone means nothing and all that matters

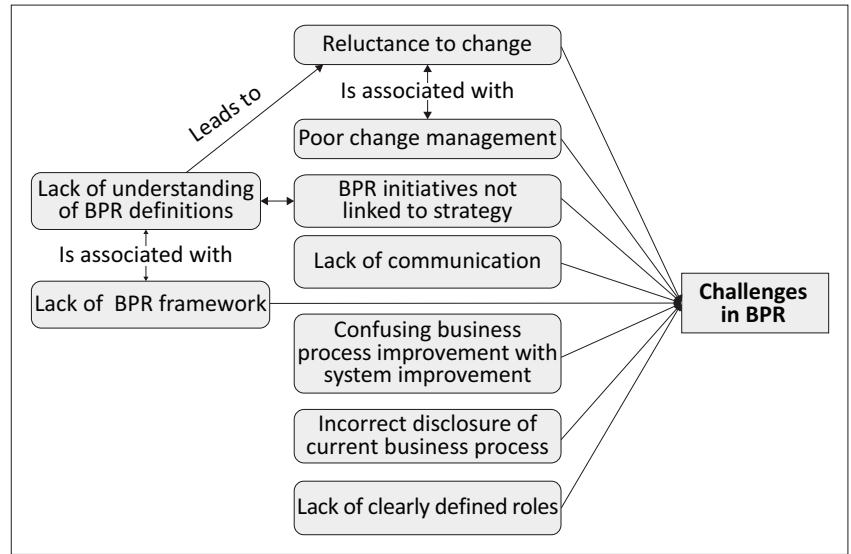

$B P R$, Business process re-engineering.

FIGURE 2: Business process re-engineering challenges.

are the duties. All interviewees performed BPR somehow, even though this would not be obvious at face value. In considering some of these roles, it is not obvious that they are related to BPR but the activities they performed are indeed related to BPR:

'I am a Functional Consultant for the implementation of SAP Ariba'. (Int_2, Gender undisclosed, FC)

'My role is transformation support analyst'. (Int_11, Gender undisclosed, TSA)

\section{Challenges and constraints}

The second section of the interviewee guide is associated with the second research questions focusing on the constraint and challenges. Interviewees were asked to share the challenges they faced when carrying out BPR activities. This was done in order to determine if there were any challenges other than the ones identified in the literature review. The lack of change management, the reluctance to change, failure to understand BPR, a lack of BPR methodology, a lack of communication, BPR initiatives not linked to strategy and duplication of efforts were identified as major challenges faced by the interviewees who worked in financial institutions:

'Due to my project role, being that of a contracted functional consultant, most of the challenges arose from internal conflicts with individuals from the business on the amendments proposed to their day-to-day activities and processes. Most of these individuals were resistant to the proposed changes from the project'. (Int_2, Gender undisclosed, FC)

'There is also a gap in a change management'. (Int_5, Gender undisclosed, BPS)

'In some cases, the system changes or upgrades changed other functions in the operations which are completely different from the initial intent. The main purpose of the upgrade would be met but other functions would be changed without us noticing'. (Int_11, Gender undisclosed, TSA)

'BPR initiatives are not linked to organisational strategy'. (Int_1, Gender undisclosed, BPR)

'Business process analyst proposals are not always in line with the various changes in other projects in the organisation'. (Int_2, Gender undisclosed, FC) 
Figure 2 depicts the challenges that were identified through the interviews and how the challenges are connected to each other within the theme of challenges.

Even though interviewees did not mention the lack of planning and monitoring as a challenge, they mentioned proper planning as a success factor. This proves that the interviewees had encountered some level of improper planning when conducting BPR initiatives.

Furthermore, the literature review did not explicitly reveal the problem of BPR projects not linking with strategy as a challenge. However, it was suggested that the project expectations and deliverables should be defined upfront, which is something that could be performed to close the linkage gap. Therefore, this challenge could be added as a new challenge in the literature.

\section{Success factors}

The success factors raised by the interviewees include time management, proper planning, proper change management, proper communication and ensuring that BPR initiatives are initiated from the top, which means involving top management. The success factors are depicted in Figure 3.

The remaining success factors such as business needs analysis, a top-down approach, the ability to measure engineered processes and the definition of the methodology are associated with BPR as these are activities that BPR workers would need to focus on when working on BPR initiatives. However, these success factors are not explicitly mentioned in the literature review and are therefore added to the conceptual framework.

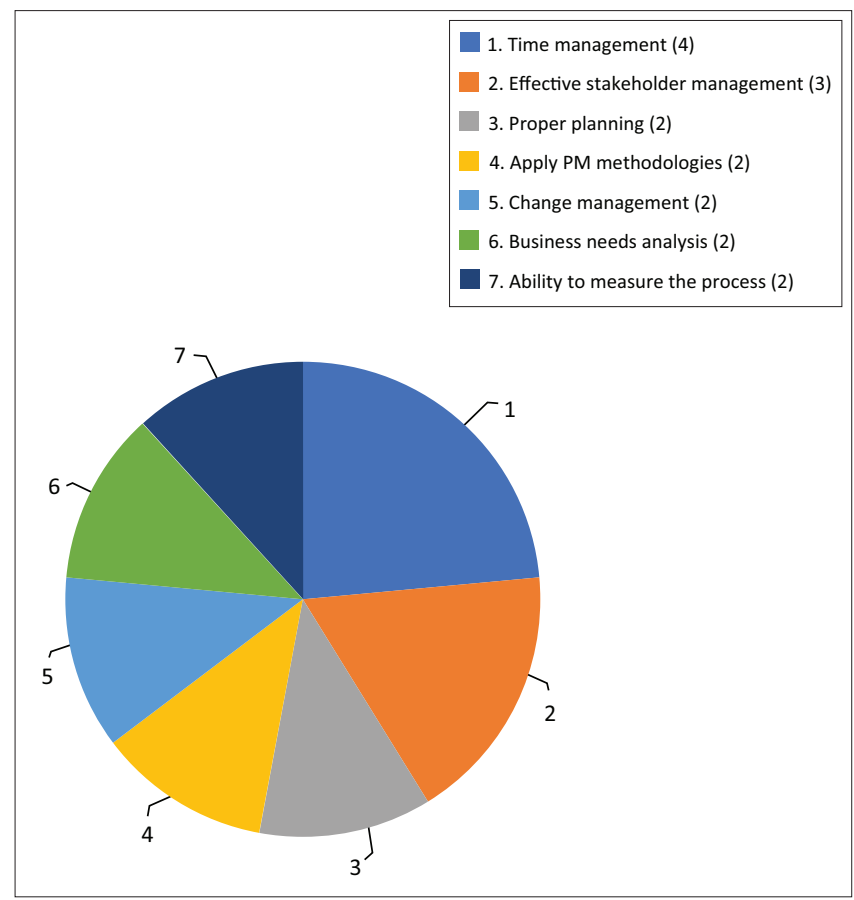

FIGURE 3: Business process re-engineering success factors.
'I think as BPR we have kind of mastered the time management skills and we just make sure that we deliver projects within the set timelines and specified times'. (Int_4, Gender undisclosed, BPR)

'Effective stakeholder engagements addressing the detailed proposed process changes ....' (Int_2, Gender undisclosed, FC)

'A BPR project is not that different from a normal project as you also have to be strict in ensuring that you adhere to the set methodologies'. (Int_9, Gender undisclosed, BA)

Interviewees were asked if they had defined BPR frameworks in order to determine if they used certain documents to guide them when conducting BPR initiatives. Three interviewees indicated that they had defined frameworks, whereas eight interviewees did not.

Int_4 indicated that their BPR framework was not completed. Therefore, they used the Business Analysis Body of Knowledge (BABOK) system to conduct BPR. However, BABOK should not be considered as it focuses more on the business analysis aspect and not necessarily on BPR (International Institute of Business Analysis 2009). Int_3 indicated that the framework was defined but not in use because of resistance from users.

Therefore, Int_3 reiterated the importance of change management in a BPR project.

It was also noted that only three of the eight interviewees who had indicated that they did not have a framework mentioned the lack of a framework as a challenge. This means that some organisations still perform BPR initiatives on a trial-and-error basis, resulting in project failure.

One interviewee said they did not have a BPR-specific framework. They used a project framework, which contained BPR elements. This means that the BPR frameworks can be customised to suit different projects. However, even in those instances, the key aspects, such as vision definition, may still need to be catered for in the customised methodology.

\section{Components of a recommended business process re-engineering framework}

Figure 4 depicts a conceptual framework that was compiled after engagements with the interviewees. The conceptual framework is a combination of project management phases, BPR and results from the interviews (Swartz 2018). It indicates that BPR activities are conducted once projects are initiated (Carmo Caccia-Bava, Valerie \& Guimaraes 2013). It also shows that BPR activities do not take place in isolation, but run in parallel with projects and in line with project principles. The change management element will run across all phases to ensure that changes are transitioned smoothly throughout the BPR project (Madushela \& Pretorius 2017; Van der Aalst et al. 2016).

The recommended framework's components were included based on the following: 


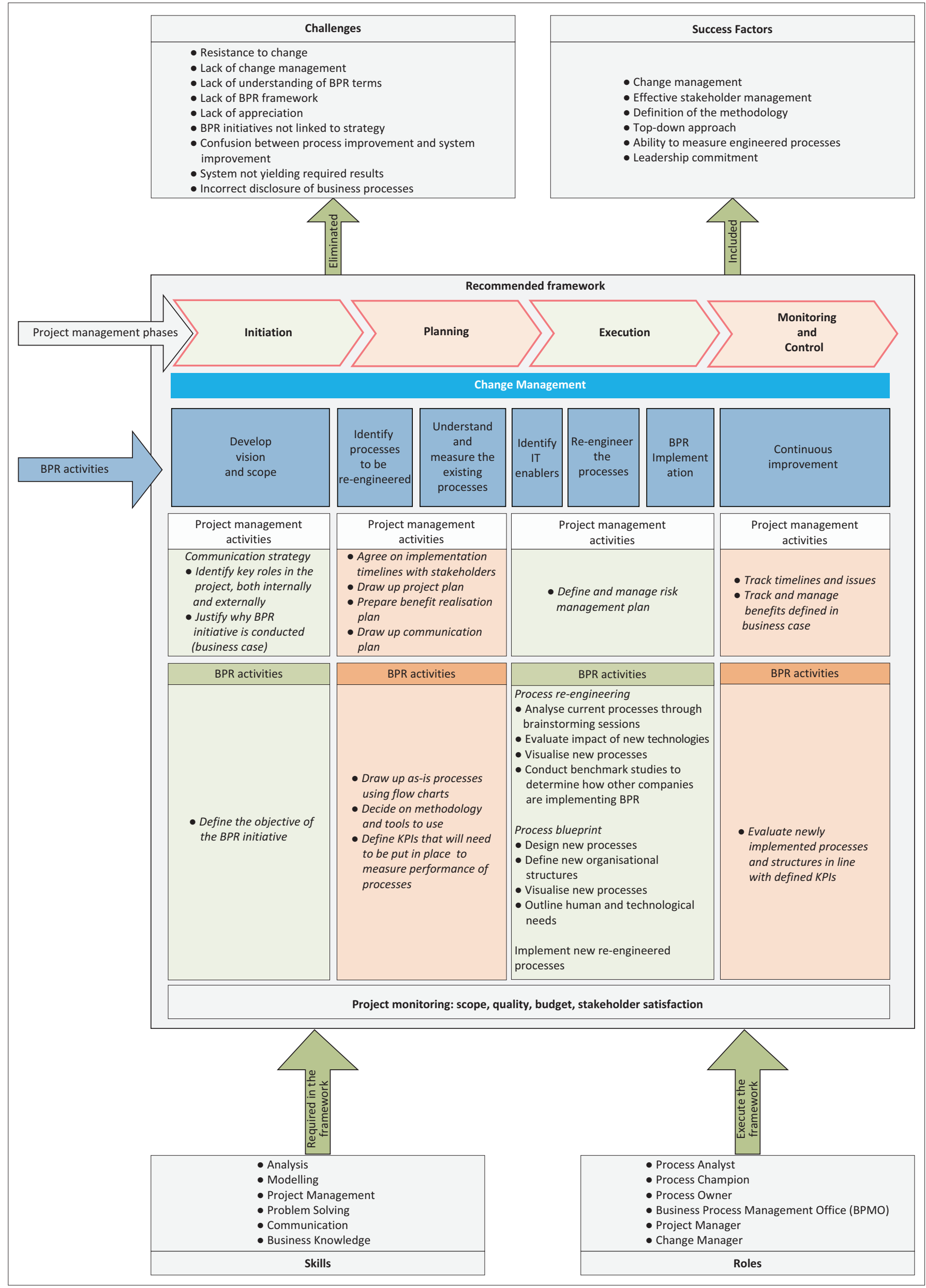

$B P R$, business process re-engineering.

FIGURE 4: Conceptual business process re-engineering framework. 
- The challenges were identified from the literature review and confirmed by the interviewees. Eliminating or reducing the challenges improves the success rate.

- Various success factors were identified from the literature review. As is the case with the challenges, the interviewees confirmed the success factors.

- The major part of the framework consists of the traditional project lifecycle (Project Management Institute 2017), change management (Hornstein 2015) and traditional BPR activities (Attaran 2004; Madushela \& Pretorius 2017). The purpose of this articleisnot to investigate theappropriateness of these components. Any BPR project that is in essence an IT/IS project, should follow these best practices.

- The last component of the framework focuses on the skills and roles. The various roles should be clearly identified, and the necessary responsibilities should be attributed to the roles. The incumbents of these roles should also have the necessary and appropriate skills.

\section{Discussion}

The aim of this study was to design a conceptual framework that could be used by financial institutions to combat the challenges faced with regard to BPR projects. The challenges that were identified from both the literature review and the data collection process were considered and removed during the definition of the framework.

These challenges were resistance to change, lack of change management, lack of understanding of the term 'BPR', lack of a BPR framework, lack of appreciation, BPR initiatives not linked to strategy, confusion between process improvement and system improvement, systems not yielding the required results and incorrect disclosure of business processes. The reluctance to change and the lack of change management were identified by multiple interviewees as major challenges. Because of these challenges, there was a lack of buy-in from key stakeholders and this resulted in commotion in BPR initiatives. Another aspect that was identified as a challenge was the lack of understanding of what BPR is. Consequently, the end-users did not buy into BPR because of the lack of understanding of what benefits the initiatives would hold for them. The BPR workers sometimes embarked on the initiatives without proper guidelines, which resulted in not delivering what they were supposed to deliver. Another challenge that was mentioned was that BPR projects were not initiated with a strategy in mind, which resulted in a lack of allocation of budget and resources.

On the other hand, the factors that could ensure success in BPR were considered and the framework was designed to include these elements. These factors were change management, effective stakeholder management, a definition of the methodology, a top-down approach and an ability to measure engineered processes. The change management element was added to cut across all phases as it was envisioned that it would be performed across all activities. The activities that had to do with stakeholder engagement included agreeing on implementation timelines with stakeholders, drawing up project plans, preparing benefit realisation plans and drawing up a communication plan. These activities are performed during the planning phase by the project management team. Time management is when the team ensures that their timelines are stipulated and discussed with the relevant people. Proper planning involves the entire organisation in planning BPR initiatives, thus ensuring that the BPR team is aware of their role in the initiative and that they know what is expected of them.

\section{Conclusion}

The study focused on developing a conceptual framework that could be used to guide BPR projects within financial institutions. The literature review suggested aspects that needed to be included in a BPR framework to ensure the success of BPR projects. These aspects included specifying principles and deciding on the methodology to be followed and the tools to be used when conducting BPR projects.

The authors then sought to understand the principles needed to be considered when working on BPR projects. A conceptual framework was developed and it included steps that need to be performed by BPR teams and those that need to be performed by project management to support the BPR initiatives.

The research shows that financial institutions have not defined roles aligned with the roles recommended for BPR. There are still roles such as transformation analysts and enterprise architects conducting BPR. This leads to experts doing things outside of their BPR role, which can lead to duplication of effort and a lack of segregation of duties. This situation has opened the eyes of the researcher in the sense that he or she now realises that the role can be different from the duties that are performed. Therefore, it is important not to consider the role only but also what the different roles entail. This lesson may be used in future research.

Financial institutions are still struggling with the implementation of BPR projects because of their lack of understanding of what BPR entails. It can be concluded that this is because of the lack of defined methodologies and clearly defined roles.

The interviewees felt very strongly about the introduction of change management as it ensures the success of BPR projects. The introduction of change management ensures that users are introduced and taken through BPR projects from inception to the end in order to prevent users from being reluctant to change. This then means that even BPR experts would need to be thoroughly workshopped on the framework to ensure that they understand what is required and that they are able to use it in future BPR projects.

The importance of project management in BPR has been identified through the literature review and was later affirmed by interviewees. The interviewees mentioned time management, effective communication and proper planning as key components. This confirms that project management needs to be part of a BPR framework as BPR projects cannot succeed without them. 
The interviewees indicated process analysis and process optimisation as key skills in BPR. This means that BPR experts must master these skills and must be taught how to analyse and optimise processes. The framework therefore needs to guide users on how to perform the skills to excel in BPR. Moreover, organisations need to find people with these skills when hiring BPR experts.

The interviewees also indicated that they needed a framework to guide their activities as this would provide the project management elements currently missing in their projects. They confirmed that the framework would assist with clear articulation of different activities performed between project management and BPR.

The conceptual framework will assist BPR experts by providing them with guidelines when conducting BPR activities. These experts will then be able to identify the project management phases of the BPR projects and link those with BPR activities that need to be performed. It will also enable project management resources to plan for BPR projects in terms of knowing which skills to source for BPR projects.

The challenges that are faced in BPR will be visible to BPR experts and they will be able to prevent those from happening. Furthermore, the experts, with the assistance of change management and project management, will be able to introduce the success factors to the projects.

Future research may include reviewing whether the defined framework has worked as anticipated or whether it needs to be amended. This may include identifying aspects that do not work and those that work well. The thinking here is that users may start identifying things that are not working in the framework once they start implementing it. The authors believe that the change management aspect needs to be understood further as it is a discipline on its own. Financial institutions need to provide ways of ensuring that change management is conducted for all BPR initiatives. Therefore, further research can include researching in detail how change management may be incorporated in $\mathrm{BPR}$, including specifying the detailed activities of what change managers do in a BPR project. Another potential research project may be to conduct research on how to enforce the framework and what to do if BPR experts do not follow the framework.

\section{Acknowledgements Competing interests}

The authors declare that they have no financial or personal relationships that may have inappropriately influenced them in writing this article.

\section{Authors' contributions}

A.N. and C.M. contributed equally to this article.

\section{Funding information}

This study received no specific funding from any agency in the public, commercial or non-profit sectors.

\section{Data availability statement}

Data that support the findings of this study can be obtained from the corresponding author, C.M., upon reasonable request.

\section{Disclaimer}

The views and opinions expressed in this article are those of the authors and do not necessarily reflect the official policy or position of any affiliated agency of the authors.

\section{References}

Aguilar-Savén, R.S., 2004, 'Business process modelling: Review and framework', International Journal of Production Economics 90(2), 129-149. https://doi. org/10.1016/S0925-5273(03)00102-6

Amoroso, D.L., 1998, 'Developing a model to understand reengineering project success', Paper Presented at the Proceedings of the Thirty-First Hawaii International Conference on System Sciences, IEEE, Kohala Coast, HI, 09th January 1998.

Antony, J., 2004, 'Some pros and cons of six sigma: An academic perspective', The TQM Magazine 16(4), 303-306. https://doi.org/10.1108/09544780410541945

Attaran, M., 2004, 'Exploring the relationship between information technology and business process reengineering', Information \& Management 41(5), 585-596. https://doi.org/10.1016/S0378-7206(03)00098-3

Bucher, T. \& Winter, R., 2009, 'Project types of business process management: Towards a scenario structure to enable situational method engineering for business process management', Business Process Management Journal 15(4), 548-568. https://doi.org/10.1108/14637150910975534

Carmo Caccia-Bava, M., Valerie, C.K.G. \& Guimaraes, T., 2013, 'Important factors for success in hospital BPR project phases', International Journal of Health Care Quality Assurance 26(8), 729-745. https://doi.org/10.1108/IJHCQA-01-2012-0007

Chakraborty, A. \& Leyer, M., 2013, 'Developing a six sigma framework: Perspectives from financial service companies', International Journal of Quality \& Reliability Management 30(3), 256-279. https://doi.org/10.1108/02656711311299836

Climent, C., Mula, J. \& Hernández Jorge, E., 2009, 'Improving the business processes of a bank', Business Process Management Journal 15(2), 201-224. https://doi. org10.1108/14637150910949452

Darmani, A. \& Hanafizadeh, P., 2013, 'Business process portfolio selection in reengineering projects', Business Process Management Journal 19(6), 892-916. https://doi.org/10.1108/BPMJ-08-2011-0052

Evans, G.N., Mason-Jones, R. \& Towill, D.R., 1999, 'The scope paradigm of business process re-engineering', Business Process Management Journal 5(2), 121-136. https://doi.org10.1108/14637159910269683

Flick, U. (ed.), 2013, The SAGE handbook of qualitative data analysis, SAGE, London.

Foerster, A., Engels, G. \& Schattkowsky, T., 2005, 'Activity diagram patterns for modeling quality constraints in business processes', Paper Presented at the Model Driven Engineering Languages and Systems, Berlin, Heidelberg, 02-07th October.

For Choi, C. \& Chan, S.L., 1997, 'Business process re-engineering: Evocation, elucidation and exploration', Business Process Management Journal 3(1), 39-63. https://doi.org/10.1108/14637159710161576

Hammer, M. \& Champy, J., 1993, 'Reengineering the corporation: A manifesto for business revolution', Business Horizons 36(5), 90-91. https://doi.org/10.1016/ S0007-6813(05)80064-3

Hornstein, H.A., 2015, 'The integration of project management and organizational change management is now a necessity', International Journal of Project Management 33(2), 291-298. https://doi.org/10.1016/j.ijproman.2014.08.005

Indulska, M., Recker, J., Rosemann, M. \& Green, P., 2009, 'Business process modeling: Current issues and future challenges', Paper Presented at the Advanced Information Systems Engineering, Berlin, Heidelberg, 08-12th June.

International Institute of Business Analysis, 2009, A guide to the business analysis body of knowledge (BABOK Guide), 2nd edn., Toronto: International Institute of Business Analysis.

Kader, I.A., \& Dwolatzky, B., 2016, 'Deriving a research agenda for a financial service industry's methodology for carrying out business process re-engineering', South African Journal of Industrial Engineering 27, 102-111. http://dx.doi. org/10.7166/27-1-592

Kettinger, W.J., James, T.C.T. \& Guha, S., 1997, 'Business process change: A study of methodologies, techniques, and tools', MIS Quarterly 21(1), 55-80. https://doi. org/10.2307/249742

Kostoff, R.N., 1999, 'Science and technology innovation', Technovation 19(10), 593-604. https://doi.org/10.1016/S0166-4972(99)00084-X 
Kumar, D. \& Bhatia, A., 2012, 'BPR: Organization culture, best practices and future trends', International Journal of Computer Applications 44(23), 1-5. https://doi. org/10.5120/6424-8653

Lindsay, A., Downs, D. \& Lunn, K., 2003, 'Business processes - Attempts to find a definition', Information and Software Technology 45(15), 1015-1019. https://doi. org/10.1016/S0950-5849(03)00129-0

Long, K.A., 2012, 'Process roles - Who are the process owners?', Business Rules Journal 13(9), viewed 13 May 2020, from http://www.brcommunity.com/a2012/ b668.html.

Luca, M., 2014, 'Business process reengineering', Paper Presented at the Risk in Contemporary Economy, Galati, 09-10th May.

Madushela, N. \& Pretorius, J.H.C., 2017, 'An integrated approach to business process reengineering management', Paper presented at the World Congress on Engineering 2017, London, 05-07th July.

Markus, M.L. \& Jacobson, D.D., 2010, 'Business process governance', in J. Vom Brocke \& M. Rosemann (eds.), Handbook on business process management 2: Strategic alignment, governance, people and culture, pp. 201-222, Springer Berlin Heidelberg, Berlin, Heidelberg.

Mendling, J., Reijers, H.A. \& Cardoso, J., 2007, 'What makes process models understandable?', Paper Presented at the Business Process Management, Berlin, Heidelberg, 24-28th September.

Mmereki, R.N. \& Moruisi, G.M., 2013, 'Challenges in implementation of business process re-engineering in Botswana public hospitals', International Journal on Customer Relations 1(1), 31-37.

Novikov, V.S., Pykhtin A.I., Gureva, M.A., Sozinova, A.A. \& Prokhorova, M.P., 2016 'Re-engineering as the process of business adaptations', International Journal of Economics and Financial Issues 6(Suppl 1), 126-132.

Project Management Institute, 2017, A guide to the project management body of knowledge (PMBOK ${ }^{\circledast}$ guide), 6th edn., Project Management Institute, Newtown Square, PA.
Ringim, K.J., Razalli, M.R. \& Hasnan, N., 2011, 'Effect of business process reengineering factors on organizational performance of Nigerian banks: Information technology capability as the moderating factor', International Journal of Business and Social capability as the moder
Science 2(13), 198-201.

Santana, A.F.L., Alves, C.F., Santos, H.R.M. \& De Lima Cavalcanti Felix, A., 2011, 'BPM Governance: An exploratory study in public organizations', Paper Presented at the Enterprise, Business-Process and Information Systems Modeling, Berlin, Heidelberg, 20-21st June.

Seethamraju, R. \& Marjanovic, O., 2009, 'Role of process knowledge in business process improvement methodology: A case study', Business Process Management Journal 15(6), 920-936. https://doi.org/10.1108/14637150911003784

Swartz, E.M.J., 2018, 'Challenges to the implementation of business process reengineering of the recruitment process in the Ministry of Fisheries and Marine Resources, Namibia', Master in Public Administration, University of Stellenbosch, Stellenbosch.

Vakola, M. \& Rezgui, Y., 2000, 'Critique of existing business process re-engineering methodologies: The development and implementation of a new methodology', Business Process Management Journal 6(3), 238-250. https://doi. org/10.1108/14637150010325453

Van der Aalst, W.M.P., La Rosa, M. \& Santoro, F.M., 2016, 'Business process management', Business \& Information Systems Engineering 58(1), 1-6. https:// doi.org/10.1007/s12599-015-0409-x

Vikas, M. \& Bharti, S., 2018, 'Correlation between business process management and organizational performance: A study of Bank X', International Journal of Engineering and Management Research 8(2), 209-213. https://doi.org/10.31033/ ijemr.v8i02.11864

Vom Brocke, J., Schmiedel, T., Recker, J., Trkman, P., Mertens, W. \& Viaene, S. 2014 , 'Ten principles of good business process management', Business Proces Management Journal 20(4), 530-548. https://doi.org/10.1108/BPMJ-06 2013-0074

Yin, R.K., 2014, Case study research: Design and methods, 5th edn., SAGE, London. 